\title{
Safety and immunogenicity of a delta inulin-adjuvanted inactivated Japanese encephalitis virus vaccine in pregnant mares and foals
}

\author{
Helle Bielefeldt-Ohmann ${ }^{1,2^{*}}$, Natalie A Prow ${ }^{2,3}$, Wenqi Wang ${ }^{1}$, Cindy SE Tan ${ }^{2,3}$, Mitchell Coyle ${ }^{4}$, Alysha Douma ${ }^{4}$,
} Jody Hobson-Peters ${ }^{2,3}$, Lisa Kidd ${ }^{1}$, Roy A Hall ${ }^{2,3}$ and Nikolai Petrovsky ${ }^{5,6}$

\begin{abstract}
In 2011, following severe flooding in Eastern Australia, an unprecedented epidemic of equine encephalitis occurred in South-Eastern Australia, caused by Murray Valley encephalitis virus (MVEV) and a new variant strain of Kunjin virus, a subtype of West Nile virus $\left(W N V_{K U N}\right)$. This prompted us to assess whether a delta inulin-adjuvanted, inactivated cell culture-derived Japanese encephalitis virus (JEV) vaccine (JE-ADVAX ${ }^{\mathrm{TM}}$ ) could be used in horses, including pregnant mares and foals, to not only induce immunity to JEV, but also elicit cross-protective antibodies against MVEV and

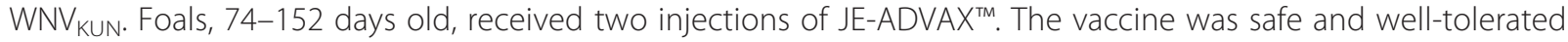
and induced a strong JEV-neutralizing antibody response in all foals. MVEV and WNV KUN $_{\text {antibody cross-reactivity }}$ was seen in $33 \%$ and $42 \%$ of the immunized foals, respectively. JE-ADVAX ${ }^{\mathrm{TM}}$ was also safe and well-tolerated in pregnant mares and induced high JEV-neutralizing titers. The neutralizing activity was passively transferred to their foals via colostrum. Foals that acquired passive immunity to JEV via maternal antibodies then were immunized with JE-ADVAX ${ }^{\mathrm{TM}}$ at 36-83 days of age, showed evidence of maternal antibody interference with low peak antibody titers post-immunization when compared to immunized foals of JEV-naïve dams. Nevertheless, when given a single JE-ADVAX ${ }^{\mathrm{TM}}$ booster immunization as yearlings, these animals developed a rapid and robust JEV-neutralizing antibody response, indicating that they were successfully primed to JEV when immunized as foals, despite the presence of maternal antibodies. Overall, JE-ADVAX ${ }^{\mathrm{TM}}$ appears safe and well-tolerated in pregnant mares and young foals and induces protective levels of JEV neutralizing antibodies with partial cross-neutralization of MVEV and WNV KUN.
\end{abstract}

\section{Introduction}

Flaviviruses of the Japanese encephalitis virus (JEV) serocomplex are amongst the most important encephalitic viruses worldwide, affecting humans, wild birds, and several mammalian species, including domestic animal species such as horses. JEV is the leading cause of viral encephalitis in Asia, where 2-3 billion people are at risk of contracting the disease [1,2]. Annually, 35 000 cases of JE are reported with a case fatality rate of nearly $30 \%$ and more than $50 \%$ of the survivors having neurological

\footnotetext{
* Correspondence: h.bielefeldtohmann1@uq.edu.au

'School of Veterinary Science, University of Queensland, Gatton Campus,

Gatton, Qld 4343, Australia

${ }^{2}$ Australian Infectious Diseases Research Centre, University of Queensland, St. Lucia, Qld 4078, Australia

Full list of author information is available at the end of the article
}

sequelae. Clinical manifestations vary and may include fever, headache, a change in mental status, seizures, tremors, generalised paresis, hypertonia and loss of coordination [3]. The clinical course in horses resembles that found in humans [4-7] with the majority of equine JEV infections being subclinical [8]. There is an estimated incidence of JE of $0.05 \%$ of JEV infections with a JE case fatality rate of $\sim 50 \%$. Treatment of JE patients, whether humans or horses, in the absence of availability of antiviral compounds, is supportive and the best means of preventing JE is immunization [9].

An inactivated JEV vaccine, developed in Japan in the 1960s (JE-VAX), dramatically reduced the number of human and equine cases of JE in that country [10]. However, this vaccine ceased to be manufactured in 2005 , due to 
perceived safety problems and excessive reactogenicity, with subsequent JEV vaccines being developed based on inactivated virus grown in cell culture $[10,11]$.

Vaccination of thoroughbred horses against JEV is mandatory in several Asian countries. However, in many countries there is currently no widely available and approved equine JEV vaccine resulting in potential off-label human vaccine use in horses. For example, vaccine failure and fatal encephalitis due to naturally acquired JEV infection has been reported in a racing horse imported from Australia into Hong Kong [5]. Cases of equine JE have the potential to cause significant adverse economic effect on the horse industry, which is estimated to contribute greater than $\$ 6$ billion to the GDP in Australia alone [12].

An inactivated Vero cell culture-derived JEV vaccine combined with delta inulin adjuvant (JE-ADVAX ${ }^{\mathrm{Tm}}$ ) was previously tested in mice and adult horses and shown to have superior immunogenicity compared to the nowdiscontinued JE-VAX as well as a recently licensed, alumadjuvanted cell culture-derived vaccine (JESPECT ${ }^{\oplus}$, Novartis) [13]. The primary aim of the present study was to undertake vaccine efficacy and safety trials of the new JE-ADVAX ${ }^{\mathrm{mx}}$ vaccine in pregnant mares and in foals without or with passively acquired maternal antibodies. A second aim was to explore the potential ability of the JE-ADVAX ${ }^{\mathrm{mm}}$ vaccine to induce cross-reactivity and cross-protection against two related viruses, Murray Valley encephalitis virus (MVEV) and a new equine-virulent $\mathrm{WNV}_{\mathrm{KUN}}$ strain (strain NSW2011), which appeared in South-East Australia in early 2011 and caused a large epidemic of equine encephalitis [14,15]. Given the unlikely future development of equine vaccines specifically against $\mathrm{MVEV}$ and $\mathrm{WNV}_{\mathrm{KUN}}$, it would be useful if an adjuvanted JEV vaccine could provide cross-protection against these related flaviviruses.

In the present report we demonstrate safety and efficacy of the JE-ADVAX ${ }^{\mathrm{si}}$ vaccine in young foals and pregnant mares. Foals born to unvaccinated mares responded to the vaccine with long-lasting humoral immunity, while foals with passively acquired maternal JEV antibodies had a blunted response to primary immunization, but after a vaccine booster as yearlings had a robust JEV-specific response indicating that memory $B$ cells had been successfully primed during the primary immunization despite interference from maternal antibodies.

\section{Materials and methods}

\section{Antigen and adjuvant}

The Vero cell culture-grown inactivated JEV vaccine (Beijing-1 strain) [16] was obtained from the Kitasato Institute, Japan. The Advax ${ }^{\mathrm{mt}}$ adjuvant was described in detail in Lobigs et al. [13]. Briefly, Advax adjuvant is based on microparticulate delta inulin [17], and was obtained from Vaxine Pty Ltd, Adelaide, Australia. Advax ${ }^{\mathrm{Tm}}$ is supplied as a sterile, preservative-free, fine particulate suspension of delta inulin particles in a phosphate buffer. The vaccine antigen and Advax adjuvant were mixed together less than two hours prior to inoculation and the mixture kept on wet ice until injected.

\section{Animals, vaccination protocol and sample collection}

The studies were approved by the University of Queensland Animal Ethics Committee (AEC nos. SVS/306/11/ VAXINE and SVS/298/13/VAXINE), and carried out in accordance with the ARC/NHMRC guidelines for ethical use of animals in research. A total of 53 thoroughbred and standard bred horses were enrolled in the studies (Tables 1, 2, 3 and 4). All horses were held in paddocks at the UQ Gatton Campus throughout the studies and received supplementary feed when needed. The first cohort of 19 foals, 74-152 days of age at first vaccination, were born to non-vaccinated mares and were all seronegative for flavivirus antibodies at entry into the trial (Table 3). Twelve foals were vaccinated with the Advaxadjuvanted JEV-vaccine, while seven foals received the adjuvant only. Seventeen mares in the second trimester of pregnancy were enrolled in the second phase, with 11 mares receiving the JEV-antigen plus Advax and six mares receiving adjuvant only. Two of the JEV-vaccinated mares had pre-existing antibodies specific for flaviviruses other than JEV, MVEV or WNV (data not shown; [18]). The foals born to the mares were subsequently enrolled in the third phase of the study (see below).

Vaccination was by subcutaneous inoculation on the rump (first foal cohort) or neck (mares and second foal cohort) in a volume of $150 \mu \mathrm{L}$. For both foals and mares the initial vaccine dose was $12 \mu \mathrm{g} J E V$-antigen plus $20 \mathrm{mg} \mathrm{Advax}{ }^{\mathrm{mm}}$ and the booster vaccination, given four weeks later was $6 \mu \mathrm{g} \mathrm{JEV}$-antigen and $20 \mathrm{mg} \operatorname{Advax}^{\mathrm{Tm}}$. Blood samples were collected at each vaccination event and then at intervals of 4-36 weeks for up to 10 months post vaccination (Figure 1). The foals born to vaccinated mares were bled at birth, before colostrum uptake, and again $12 \mathrm{~h}$ after colostrum uptake, and a colostrum sample was obtained from the mares at foaling. This second cohort of foals was initially vaccinated at 36-83 days of age with a schedule similar to the first foalcohort. They subsequently also received one additional vaccine booster $\left(6 \mu \mathrm{g} J E V\right.$-antigen and $20 \mathrm{mg}$ Advax $\left.{ }^{\mathrm{Tm}}\right)$ 10 months after the initial vaccination and blood samples were collected 2, 6, 12 and 18 weeks post vaccination. The six foals born to Advax ${ }^{\mathrm{Tm}}$-only treated control mares were left untreated. Two of these unvaccinated foals were subsequently lost due to study-unrelated causes (birth complications and trauma, respectively).

Following each vaccine injection the animals were clinically assessed daily for 3-4 days while kept in small holding paddocks. The injection sites were inspected and 
Table 1 Flavivirus specific antibody levels in foals born to flavivirus antibody-negative mares and vaccinated at 74-152 days of age ${ }^{\mathrm{a}}$

\begin{tabular}{|c|c|c|c|c|c|c|c|c|c|c|}
\hline \multirow[b]{2}{*}{ Foal \# } & \multirow{2}{*}{$\begin{array}{l}\text { Age at } \\
\text { Day } 0\end{array}$} & \multicolumn{3}{|c|}{ JEV neutralising antibodies } & \multicolumn{3}{|c|}{ MVEV neutralising antibodies } & \multicolumn{3}{|c|}{ WNV $_{\text {KUN }}$ neutralising antibodies } \\
\hline & & Day 28 (boost) & Day 56 & Day 308 & Day 28 (boost) & Day 56 & Day 308 & Day 28 (boost) & Day 56 & Day 308 \\
\hline $1 F 11$ & 74 & & 80 & 20 & & $<20$ & $<20$ & & $<20$ & 20 \\
\hline 5 F11 & 115 & 40 & 160 & 160 & $<20$ & $<20$ & 20 & $<20$ & $<20$ & $<20$ \\
\hline $7 \mathrm{~F} 11$ & 108 & & 160 & 40 & & $<20$ & $<20$ & & 40 & $<20$ \\
\hline 8 F11 & 132 & & 160 & $<20$ & & 20 & $<20$ & & 40 & $<20$ \\
\hline $11 \mathrm{~F} 11$ & 119 & & 160 & 80 & & 20 & $<20$ & & 40 & $<20$ \\
\hline 12 F11 & 81 & 40 & 1280 & 80 & $<20$ & 80 & $<20$ & $<20$ & 80 & $<20$ \\
\hline 14 F11 & 123 & & 320 & 20 & & $<20$ & 20 & & 20 & $<20$ \\
\hline 15 F11 & 125 & & 320 & $<20$ & & $<20$ & $<20$ & & 40 & 20 \\
\hline 17 F11 & 111 & & 320 & 20 & & $<20$ & $<20$ & & $<20$ & $<20$ \\
\hline $21 \mathrm{~F} 11$ & 97 & & 320 & $<20$ & & 20 & $<20$ & & $<20$ & 20 \\
\hline 26 F11 & 116 & 40 & 1280 & 80 & 20 & 80 & 20 & $<20$ & $<20$ & 20 \\
\hline 30 F11 & 111 & & 160 & 20 & & $<20$ & $<20$ & & $<20$ & 20 \\
\hline Control A & 115 & & $<20$ & $<20$ & & $<20$ & 20 & & $<20$ & 20 \\
\hline Control G & 115 & & $<20$ & $<20$ & & $<20$ & $<20$ & & $<20$ & $<20$ \\
\hline
\end{tabular}

${ }^{a}$ Samples negative in the flavivirus (4G2) blocking ELISA were not tested in the neutralization assays. This included five control foals (B-F), aged 125 to 152 days, which are not listed in the table.

any local reaction recorded. Body temperature and general demeanor were also recorded. With no adverse reactions recorded the animals were then returned to the main paddocks.

\section{Flavivirus serology}

Blood samples were collected by venepuncture into sterile vacutainers (BD Biosciences, Franklin Lakes, NJ, USA) and allowed to clot at room temperature, then centrifuged at $4{ }^{\circ} \mathrm{C}$ for $10 \mathrm{~min}$ at $3500 \mathrm{rpm}$. Procured sera were stored at $-20{ }^{\circ} \mathrm{C}$ in sterile cryovials until assayed by ELISA and virus neutralization following heat inactivation at $56{ }^{\circ} \mathrm{C}$ for $30 \mathrm{~min}$. Colostrum samples were centrifuged and the nonfat fraction collected and heat-treated as for serum before testing in the ELISA and neutralization assay.

All horse sera and colostrum samples were initially screened for flavivirus-specific antibodies using an epitope- blocking ELISA [19,20] with minor modifications as described in detail in Prow et al. [18]. Samples showing $>30 \%$ inhibition in this assay were subsequently tested for neutralizing antibody reactivity to JEV (strain Nakayama), MVEV (strain 1-51) and $\mathrm{WNV}_{\mathrm{KUN}}$ (strain NSW2011). The heat-inactivated test sera were titrated in doubling dilutions from 1:20 to 1:2560 and colostrum samples in dilutions from 1:40 to $1: 5120$ as previously described in detail [18].

\section{Results}

JE-ADVAX ${ }^{\mathrm{TM}}$ responses in foals born to naïve mares

In this trial, 19 foals, aged 74-152 days and born to non-vaccinated, flavivirus sero-negative mares, were enrolled. Twelve foals received two vaccinations four weeks apart with $12 \mu \mathrm{g}$ and $6 \mu \mathrm{g} \mathrm{JE}-\mathrm{ADVAX}^{\mathrm{TM}}$, respectively. Six control foals received ADVAX ${ }^{\mathrm{TM}}$ alone without antigen.

Table 2 Flavivirus antibody responses in mares vaccinated in second trimester of pregnancy

\begin{tabular}{|c|c|c|c|c|c|c|c|c|c|}
\hline \multirow[t]{2}{*}{ Time point } & \multicolumn{3}{|c|}{ JEV neutralizing } & \multicolumn{3}{|c|}{ MVEV neutralizing } & \multicolumn{3}{|c|}{ WNV $_{\text {KUN }}$ neutralizing } \\
\hline & Positive/total & $\begin{array}{l}\text { Mean } \\
\text { titre }^{\mp}\end{array}$ & $\begin{array}{l}\text { Positive titre } \\
\text { range }\end{array}$ & Positive/total & $\begin{array}{l}\text { Mean } \\
\text { titre }^{\neq}\end{array}$ & $\begin{array}{l}\text { Positive titre } \\
\text { range }\end{array}$ & Positive/total & $\begin{array}{l}\text { Mean } \\
\text { titre }^{\neq}\end{array}$ & $\begin{array}{l}\text { Positive titre } \\
\text { range }\end{array}$ \\
\hline Day 0 (vaccination) & $0 / 11$ & - & - & $0 / 11$ & - & - & $0 / 11$ & - & - \\
\hline Day 28 (booster) & $0 / 11$ & - & - & $0 / 11$ & - & - & $2 / 11$ & 80 & $20-80$ \\
\hline Days 56-183 & $8 / 11$ & 180 & $20-320$ & $4 / 11$ & 100 & $20-160$ & $3 / 11$ & 560 & $20-1280$ \\
\hline Day 230 (7.5 months) & $11 / 11$ & 47 & $20-80$ & $9 / 11$ & 31 & $20-80$ & $2 / 11^{*}$ & 60 & $20-80$ \\
\hline Day 331 (11 months) & $7 / 11$ & 26 & $20-40$ & $4 / 11$ & 40 & $20-80$ & $2 / 11^{*}$ & 60 & $20-80$ \\
\hline
\end{tabular}

${ }^{\mp}$ mean of titres $\geq 20$.

*same two mares (\# 10 \& 33). 
Table 3 Flavivirus-specific antibodies in colostrum and serum of JE + ADVAX ${ }^{\mathrm{Tm}}$ vaccinated and unvaccinated mares at the time of foaling ${ }^{a}$

\begin{tabular}{|c|c|c|c|c|c|c|}
\hline \multirow[b]{2}{*}{ Mare \# } & \multicolumn{3}{|l|}{ Colostrum } & \multicolumn{3}{|l|}{ Serum } \\
\hline & $\begin{array}{l}\text { JEV neutralizing } \\
\text { antibody titres }\end{array}$ & $\begin{array}{l}\text { MVEV neutralizing } \\
\text { antibody titres }\end{array}$ & $\begin{array}{l}\text { WNV }_{\text {KUN }} \text { neutralizing } \\
\text { antibody titres }\end{array}$ & $\begin{array}{l}\text { JEV neutralizing } \\
\text { antibody titres }\end{array}$ & $\begin{array}{l}\text { MVEV neutralizing } \\
\text { antibody titres }\end{array}$ & $\begin{array}{l}\text { WNV }_{\text {KUN }} \text { neutralizing } \\
\text { antibody titres }\end{array}$ \\
\hline 2 & 2560 & 80 & $<40$ & 40 & $<20$ & $<20$ \\
\hline 5 & 160 & $<40$ & $<40$ & 20 & 20 & $<20$ \\
\hline 8 & 640 & 80 & $<40$ & 20 & $<20$ & $<20$ \\
\hline 10 & 640 & 80 & 80 & 40 & 20 & 80 \\
\hline 11 & 320 & 40 & $<40$ & $<20$ & 20 & $<20$ \\
\hline 14 & 640 & 80 & $<40$ & 20 & $<20$ & $<20$ \\
\hline 17 & 320 & 40 & $<40$ & 40 & 40 & 40 \\
\hline 21 & 160 & 40 & $<40$ & $<20$ & $<20$ & $<20$ \\
\hline 26 & 160 & 80 & $<40$ & 20 & $<20$ & $<20$ \\
\hline 33 & 640 & 80 & 40 & 40 & 40 & 80 \\
\hline 34 & 640 & $<40$ & $<40$ & 40 & $<20$ & $<20$ \\
\hline Control $A^{b}$ & 160 & 40 & $<40$ & $<20$ & $<20$ & $<20$ \\
\hline Control B & 40 & 40 & $<40$ & $<20$ & $<20$ & $<20$ \\
\hline Control C & 320 & 40 & $<40$ & $<20$ & $<20$ & $<20$ \\
\hline
\end{tabular}

${ }^{a}$ Samples negative in the flavivirus (4G2) blocking ELISA were not tested in the neutralization assays. This included three control mares (D-F), which are not shown in the Table.

${ }^{b}$ Entered trial at time of foaling, having received neither JEV + Advax nor Advax alone.

Only mild swelling at the inoculation site was noted in some of the foals 1-3 days following subcutaneous injection on the rump. No reaction was seen in the Advax-only treated foals. Three foals had flavivirus-specific antibodies at the time of vaccine-boosting (Table 1), though none had virus-neutralizing activity. However, four weeks after the booster 12/12 (100\%) of JE-ADVAX ${ }^{\mathrm{mw}}$-vaccinated foals had high serum JEV-neutralizing antibody titres and this neutralizing activity was still present 8.5 months later in $9 / 12(75 \%)$ foals (Table 1$)$. In contrast, cross-reactivity to MVEV and $\mathrm{WNV}_{\text {KUN }}$ was generally low or absent (Table 1). Two control foals had sero-converted to flaviviruses at the last sampling, 10 months after trial commencement, presumably due to natural exposure to flaviviruses circulating in South-East Queensland [18,22,23].

\section{JE-ADVAX ${ }^{\mathrm{TM}}$ safety and immunogenicity in pregnant mares}

The JE-ADVAX ${ }^{\text {ma }}$ vaccine formulation was previously shown to be safe and immunogenic in adult horses [13], however, for licensing purposes it must also be shown to be safe in pregnant animals [21]. Therefore, 17 mares in second trimester of pregnancy were enrolled in a trial, where 11 mares received an initial dose of $12 \mu \mathrm{g}$ of JEV antigen mixed with $20 \mathrm{mg}$ of $\mathrm{ADVAX}^{\mathrm{TM}}$ subcutaneously in the neck and four weeks later were boosted with $6 \mu \mathrm{g}$ of JEV antigen plus ADVAX ${ }^{\mathrm{TM}}$. No adverse reactions were noted, other than mild swelling at the inoculation site of some mares 1-3 days following the booster vaccination. Four mares received ADVAX ${ }^{\mathrm{Tm}}$ only at the two time points and no reactions to the adjuvant were recorded. The remaining two mares received neither antigen nor adjuvant. Pre-vaccination, two of the pregnant mares had flavivirus-specific antibodies, detected in the 4G2-blocking ELISA, however, these antibodies did not neutralize JEV, MVEV or $\mathrm{WNV}_{\mathrm{KUN}}$ (Table 2). At the time of vaccine boosting (four weeks after initial dose), an additional five mares had developed flavivirus specific antibodies, detected in the blocking ELISA (data not shown), although none had measurable JEV or MVEV neutralizing antibodies. At this time point one of the mares with preimmunization flavivirus antibodies had developed a $\mathrm{WNV}_{\mathrm{KUN}}$-neutralizing titre of 80 (Table 2 and data not shown). Four weeks after the booster vaccination, 11/11 (100\%) of mares had flavivirus-specific antibodies in the blocking ELISA and of these 8/11 (72\%) had developed JEV-neutralizing antibodies, while only four (36\%) and three (27\%) had MVEV- and $\mathrm{WNV}_{\mathrm{KUN}}$-neutralizing antibodies, respectively (Table 2). Interestingly, 7.5 months following vaccination all 11 mares (100\%) had JEV-neutralizing antibodies, while nine (82\%) and two (18\%) had neutralizing antibodies to MVEV and $\mathrm{WNV}_{\mathrm{KUN}}$, respectively (Table 2). This suggests that either some animals responded slowly to the vaccine or had been naturally exposed to flaviviruses, most likely MVEV or Alfuy virus [18,22], thereby providing a boost to the original vaccine response. 
Table 4 Flavivirus specific antibody levels in foals born to vaccinated mares and vaccinated at 36-83 days of age, followed by booster vaccinations four weeks and approximately one year later

\begin{tabular}{|c|c|c|c|c|c|c|c|c|c|}
\hline \multirow[t]{2}{*}{ Time point } & \multicolumn{3}{|c|}{ JEV neutralizing } & \multicolumn{3}{|c|}{ MVEV neutralizing } & \multicolumn{3}{|c|}{ WNV $_{\text {KUN }}$ neutralizing } \\
\hline & Positive/total & $\begin{array}{l}\text { Mean } \\
\text { titre }^{\neq}\end{array}$ & $\begin{array}{l}\text { Titre } \\
\text { range }\end{array}$ & Positive/total & $\begin{array}{l}\text { Mean } \\
\text { titre }^{\neq}\end{array}$ & $\begin{array}{l}\text { Titre } \\
\text { range }\end{array}$ & Positive/total & $\begin{array}{l}\text { Mean } \\
\text { titre }^{\neq}\end{array}$ & $\begin{array}{l}\text { Titre } \\
\text { range }\end{array}$ \\
\hline Pre-suckle & $0 / 11$ & - & - & $0 / 11$ & - & - & $0 / 11$ & - & - \\
\hline Post suckle & $10 / 11$ & 46 & $<20-80$ & $8 / 11$ & 30 & $<20-40$ & $3 / 11$ & 93 & $<20-160$ \\
\hline Age 13-49 days & $3 / 10^{*}$ & 26 & $<20-40$ & $1 / 10^{*}$ & 40 & $<20-40$ & $2 / 10^{*}$ & 30 & $<20-40$ \\
\hline Vaccination & $3 / 11$ & 20 & $<20-20$ & $2 / 11$ & 20 & $<20-20$ & $1 / 11$ & 40 & $<20-40$ \\
\hline \multicolumn{10}{|l|}{ Age $36-83$ days } \\
\hline Booster 4 weeks post vaccination & $2 / 11$ & 20 & $<20-20$ & $3 / 11$ & 20 & $<20-20$ & $2 / 11$ & 20 & $<20-20$ \\
\hline \multicolumn{10}{|l|}{ Age $64-111$ days } \\
\hline 4 weeks post booster & $10 / 11$ & 88 & $<20-320$ & $10 / 11$ & 30 & $<20-40$ & $1 / 11$ & 20 & $<20-20$ \\
\hline \multicolumn{10}{|l|}{ Age $93-140$ days } \\
\hline 7 weeks post booster & $3 / 11$ & 53 & $<20-80$ & $6 / 11$ & 26 & $<20-40$ & $3 / 11$ & 20 & $<20-20$ \\
\hline \multicolumn{10}{|l|}{ Age $114-161$ days } \\
\hline 10 weeks post booster & $5 / 11$ & 24 & $<20-40$ & $0 / 11$ & - & $<20$ & $1 / 11$ & 20 & $<20-20$ \\
\hline \multicolumn{10}{|l|}{ Age 137-184 days } \\
\hline$\sim 9$ months post $1^{\text {st }}$ boost ( $2^{\text {nd }}$ boost) & $0 / 11$ & - & $<20$ & $0 / 11$ & - & $<20$ & $0 / 11$ & - & $<20$ \\
\hline \multicolumn{10}{|l|}{ Age 332-379 days } \\
\hline 2 weeks post $2^{\text {nd }}$ boost & $11 / 11$ & $>902$ & $160->2560$ & $10 / 11$ & 50 & $<20-80$ & $1 / 11$ & 20 & $<20-20$ \\
\hline \multicolumn{10}{|l|}{ Age $346-393$ days } \\
\hline 5.5 weeks post $2^{\text {nd }}$ boost & $11 / 11$ & 465 & $160-1280$ & $7 / 11$ & 17 & $<20-40$ & $0 / 11$ & - & $<20$ \\
\hline \multicolumn{10}{|l|}{ Age $370-417$ days } \\
\hline 14 weeks post $2^{\text {nd }}$ boost & $8 / 11$ & 150 & $<20-640$ & $0 / 11$ & - & $<20$ & $9 / 11$ & 31 & $<20-80$ \\
\hline \multicolumn{10}{|l|}{ Age 454-501 } \\
\hline 20 weeks post $2^{\text {nd }}$ boost & $7 / 11$ & 63 & $<20-160$ & $0 / 11$ & - & $<20$ & $0 / 11$ & - & $<20$ \\
\hline Age 498-545 days & & & & & & & & & \\
\hline
\end{tabular}

*one foal not yet born at this sampling point.

${ }^{*}$ mean of titres $\geq 20$.

The mares foaled 4.5-6 months after the initial vaccination and all had high JEV-neutralizing antibody titres in the colostrum, even though the serum-titres in two of the mares at the time of foaling were below the assay cut-off (Table 3). In 9/11 (82\%) of the mares the colostrum antibodies also neutralized MVEV, while in only 2/11 (18\%) mares did the colostrum antibodies neutralize $\mathrm{WNV}_{\mathrm{KUN}}$ (Table 3).

None of the control unvaccinated mares or mares injected with ADVAX ${ }^{\mathrm{Tw}}$ alone had flavivirus-specific antibodies, based on the pre-vaccination blocking ELISA, however, three of these mares developed flavivirus specific antibodies during the trial period (Table 3). As none of these mares had neutralizing antibodies to JEV, MVEV or $\mathrm{WNV}_{\mathrm{KUN}}$, it is most likely they sero-converted to some of the other flaviviruses commonly circulating in the area [18]. Interestingly, the colostrum of these three control mares did have neutralizing activity towards JEV and MVEV, but not to $\mathrm{WNV}_{\mathrm{KUN}}$ (Table 3).
JE-ADVAX ${ }^{\mathrm{TM}}$ responses in foals born to JEV-immune mares In the second foal trial, 11 foals born to the JE-ADVAX ${ }^{\mathrm{pm}}$ vaccinated mares (Tables 2 and 3 ) received a similar vaccine schedule to that described earlier for the first trial when they were between 36-83 days old. At vaccination, six (55\%) foals still had measurable passively transferred maternal serum antibodies to flaviviruses, as detected by the blocking ELISA, although only three (27\%) had measurable serum JEV neutralizing titres (Table 4). Nevertheless, all $11 / 11(100 \%)$ foals responded to the JE-ADVAX vaccine with antibodies detectable by the 4G2-blocking ELISA four weeks after the booster vaccination (Table 4). Of these 10 (91\%) had JEV- and 10 (91\%) MVEV-neutralizing antibodies after the booster vaccination, but the titres rapidly decreased and by 10 weeks after the booster vaccination only 5/11 (45\%) foals had low JEV-neutralizing antibody titres, none had MVEV-specific antibodies and only one had a low $\mathrm{WNV}_{\mathrm{KUN}^{-}}$-specific titre (Table 4). Four foals borne to non-vaccinated mares and left untreated 


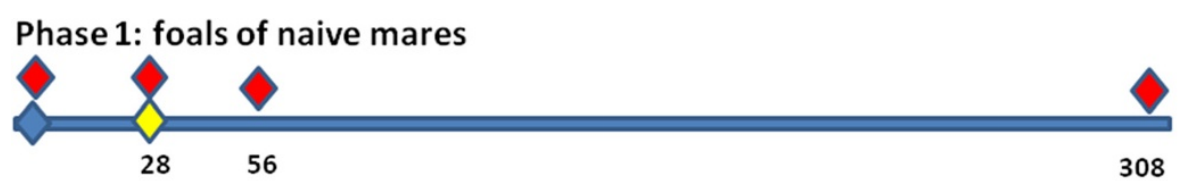

Phase 1: pregnant mares

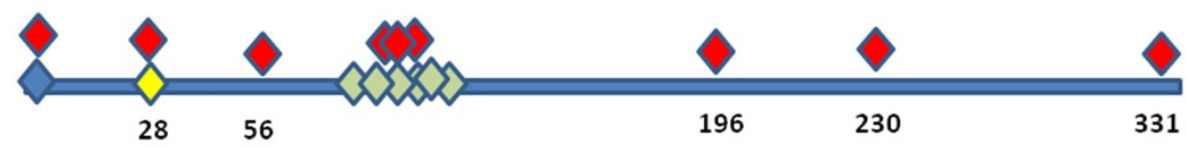

Phase 1: foals of vaccinated mares

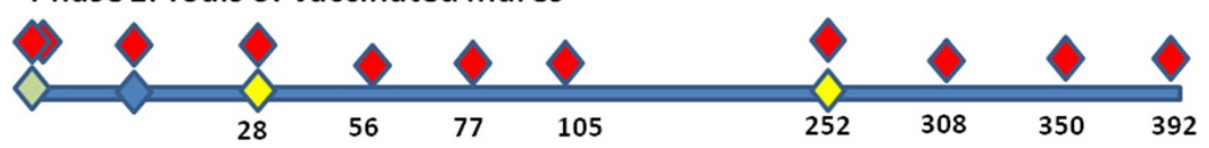

vaccination

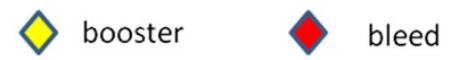

Foaling/birth

Figure 1 Schematic of the vaccination schedules for the three cohorts. The numbers under each line refer to days post-vaccination. The timelines are not to scale.

remained flavivirus sero-negative for the duration of the trial (data not shown).

When these 11 vaccinated foals were retested 10 months after the primary vaccination, only two $(18 \%)$ had flavivirusspecific antibodies detectable in the blocking ELISA, but neither had virus-neutralizing activity (Table 4). The animals, now yearlings, then received a single booster vaccination with $6 \mu \mathrm{g}$ of JE-ADVAX and were bled two, 5.5, 14 and 20 weeks post booster vaccination. All 11/11 animals were already strongly positive in the flavivirus blocking ELISA two weeks post vaccination, and 11/11 (100\%) were confirmed to have JEV-neutralizing antibodies (Table 4), indicating that the original JE-ADVAX vaccination had primed them for a rapid $B$ cell recall response despite interference of maternal antibodies. While the JEV-neutralizing antibody titres declined over the following 18 weeks, $7 / 11$ horses (63\%) still had JEV-neutralizing antibody titres $>20$ at the last bleed (Table 4). None of the yearlings had MVEV- and $\mathrm{WNV}_{\mathrm{KUN}}$-neutralizing antibodies at the time of the second booster, but two weeks after the boost 10/11 (91\%) horses had MVEV-neutralizing antibodies (Table 4). The yearlings remained negative for neutralizing antibodies to $\mathrm{WNV}_{\mathrm{KUN}}$ until three months after the booster, when 9/11 (82\%) had a detectable titre. The cross-reactive antibody activity to MVEV and $\mathrm{WNV}_{\mathrm{KUN}}$ had declined below the assay cut-off of $<20$ by 20 weeks post booster (Table 4).

\section{Discussion}

The results of this study corroborate and extend those of a previous study by Lobigs et al. [13] and show that the cell culture-derived, inactivated JE-vaccine is safe in horses of any age and when delivered with the novel polysaccharide adjuvant Advax elicits a strong JEV-specific neutralizing antibody response in both pregnant adult horses and in very young foals which lasts at least 10-11 months in the majority of the animals (Tables 1 and 2). While a $3^{\text {rd }}$ booster vaccination was not given at that stage, the results of the vaccine trial in foals with passively acquired immunity suggest that the vaccine delivers robust priming of a memory B-cell response, which results in a strong humoral recall response despite serum antibodies having decreased to undetectable levels (Table 4).

In contrast to the high level of MVEV and WNV crossprotection seen in mice with JE-ADVAX ${ }^{\mathrm{m}}$ vaccine [24] or the live Chimerivax-JE vaccine [25], cross-neutralization of $\mathrm{WNV}_{\mathrm{KUN}}$ was only present in serum of $27 \%(3 / 11)$ of mares and in $41 \%(5 / 12)$ of foals immunized with two doses of JE-ADVAX ${ }^{\mathrm{ma}}$ (Tables 1 and 2). In the foals the low $\mathrm{WNV}_{\mathrm{KUN}}$ titres detected at day 308 post primary vaccination may even be the result of boosting by natural exposure to JEV sero-complex flaviviruses, as MVEV, $\mathrm{WNV}_{\mathrm{KUN}}$ and Alfuy virus are known to circulate in the area where the horses were kept $[18,22,23]$. However, extensive JE-ADVAX dose ranging studies have not yet been performed in horses and hence with a larger vaccine dose 
higher levels of flavivirus cross-neutralization closer to the levels seen in mice may be achieved [24]. An alternative explanation might be that mice are not ideal models for equine vaccine responses [26].

As could be expected, the JEV-specific antibody titres in colostrum far exceeded those in the serum of the mares at the time of foaling (Table 3). This difference was even more notable for MVEV cross-reactive antibodies, with MVEV-neutralizing activity detectable in the colostrum of $82 \%(9 / 11)$ of immunized mares and in serum of $72 \%$ (8/11) of foals $12 \mathrm{~h}$ post colostrum uptake, despite being detectable in the serum of only $45 \%(5 / 11)$ of these mares (Tables 3 and 4). While this trial was not designed to assess the half-life of passively acquired immunity, it is nevertheless a notable finding, as it would suggest that vaccination of pregnant mares with the JE-ADVAX vaccine in areas of Australia where MVEV is endemic might confer protection of the foals against this almost invariably fatal infection [22,27-30]. In general, the cross-reactivity to MVEV was greater than that to $\mathrm{WNV}_{\mathrm{KUN}}$. Nevertheless, the results suggest that it might be possible to further enhance flavivirus cross-protection by additional vaccine boosters, as was seen in the study by Lobigs et al. [13], or increases in vaccine dose.

Two control mares, receiving Advax adjuvant only, were apparently naturally exposed to flavivirus(es) sometime between the start of the trial and foaling, giving rise to high cross-reactivity to JEV and MVEV in their colostrum (Table 3). Similarly, a control mare that received neither vaccine nor adjuvant, had high JEV- and MVEVneutralizing antibody titres in its colostrum despite only having serum neutralizing activity to Kokobera virus (titre of 40 [18]), which normally does not confer crossprotection to JEV serocomplex viruses [18,31]. Two of the foals born to these three control mares were subsequently positive for flavivirus antibodies in the 4G2blocking ELISA for a couple of months, but at no point was JEV- or MVEV-neutralizing activity detected in their serum (data not shown). This aspect was not further pursued, but it might be speculated that these were antibodies of low affinity and/or avidity and/or quickly catabolized in the foals.

The degree of interference with immune responses in young animals by passively acquired maternal antibodies may depend on the animal species, antigen type, route of vaccination and other variables [32-38]. While all the foals received flavivirus-specific antibodies in colostrum, resulting in detectable serum JEV-neutralizing antibodies in $91 \%$ of foals at $12 \mathrm{~h}$ post suckle, this neutralizing activity decreased to below detection level in all but the three youngest foals by the time of primary vaccination (Table 4), and all but one foal responded with moderately high to high JEV-neutralizing titres four weeks after the second vaccine dose. However, in the presence of maternal antibodies the antibody response to vaccination was shorter-lived, with only $5 / 11$ (45\%) foals still having JEV-neutralizing antibodies 10 weeks after the booster. Six months later all but two were negative for flavivirus antibodies in the 4G2-blocking ELISA, but all 11 animals, by then yearlings, responded to a second booster with a very rapid and robust antibody response. Thus, while vaccination at an age where passively acquired antibodies were still present prevented sustained serum neutralizing antibody responses, memory B cells were still induced in these foals immunized in the presence of passive antibodies, as reflected in their vigorous response to a single vaccine boost. This suggests that the apparent "window of susceptibility" created by vaccination in the presence of passively acquired antibodies, may not in reality be as much of a problem as generally thought [35,37-39], as even in the absence of pre-existing serum antibody, the primed memory $\mathrm{B}$ cell response is able to respond rapidly enough to control any infection. Arthropod-borne viruses initially replicate at the site of inoculation before spreading haematogenously or via the lymphatic system to local lymph nodes and beyond $[40,41]$. While the route and mechanisms of neuro-invasion by the encephalitic flaviviruses are still unknown [42], we recently described a case of MVEV-encephalitis in a horse, in which MVEV-neutralizing antibodies were present one week prior to clinical symptoms, but not two weeks prior to clinical disease [22]. This suggests that even in a primary infection the antibody response to JEV-serocomplex viruses may be relatively fast, and can be anticipated to be even faster in a recall response [43]. If this assumption is correct, then primed animals lacking detectable serum-neutralizing antibodies might still be protected by a rapid memory B cell recall response able to neutralize the virus before it spreads to the central nervous system. This is similar to the results obtained in JE-ADVAX-immunized beta-2-microglobulin knockout mice, which were still protected against JEV, despite having no detectable serum neutralizing antibody pre-challenge, thanks to a robust recall response and rapid rise in serum antibody titer in response to the challenge virus [44]. Future studies should aim to test this hypothesis in horses, since as discussed above, the murine immune response may not truly reflect that of equines [26], nor does the disease progression in mice reflect that seen in natural and experimental infections of horses with JEV, MVEV and WNV KUN ([22,45-49]; Bielefeldt-Ohmann et al., unpublished data 2013).

In conclusion, JE-ADVAX ${ }^{\mathrm{Tw}}$ was safe, well-tolerated and highly immunogenic in both young foals and in pregnant mares, in which it induced high titre JEV-specific antibodies in colostrum, thus ensuring passive transfer of protective antibodies to the newborn foals. Despite evidence of maternal antibody interference, foals of immune dams developed strong memory B cell responses to JEV, as reflected in a 
robust recall response to a single booster JE-ADVAX dose as yearlings. Although primarily designed to provide protection against JEV, some cross-neutralisation against MVEV and WNV was seen in some of the JE-ADVAX immunized horses. Future studies will test modifications to the vaccination protocol, including increasing the antigen or adjuvant dose, adding a further booster immunization, priming with JE-ADVAX and boosting with already licensed WNV vaccines $[47,50]$ or with novel WNV vaccine candidates [48,51-54] to see whether it is possible to induce cross-protection against a wider spectrum of flaviviruses.

\section{Competing interests}

NP is affiliated with Vaxine Pty, Ltd, a company with commercial interests in Advax ${ }^{T M}$, the adjuvant employed in the present studies. The authors declare that they have no competing interests.

\section{Authors' contributions}

Conceived and designed the experiments: HBO, NAP, LK, MC, RAH, NP. Performed the experiments: HBO, NAP, WW, CSET, JHP, LK, MC, AD. Analyzed the data: HBO, NAP, WW, CSET, JHP, RAH, NP. Drafted the manuscript: HBO, NAP, RAH, NP. All authors read and approved the final manuscript.

\section{Acknowledgements}

We thank Dr Mario Lobigs for constructive discussions on the study design, and Sharon Blum, Anita Barton, Dr Ristan Greer, and students at the UQ School of Veterinary Science and the UQ Gatton Campus Equine Unit for help with animal handling and sampling. The study was supported by grants from the UQ-CIEF program (RM20111110; HBO, RAH), the Australian Research Council (ARC-LP120100686; RAH, HBO et al.), and contract

HHSN272200800039C from the National Institute of Allergy and Infectious Diseases, National Institutes of Health (NP). This paper's contents are solely the responsibility of the authors and do not necessarily represent the official views of the funders.

\section{Author details}

'School of Veterinary Science, University of Queensland, Gatton Campus, Gatton, Qld 4343, Australia. ${ }^{2}$ Australian Infectious Diseases Research Centre, University of Queensland, St. Lucia, Qld 4078, Australia. ${ }^{3}$ School of Chemistry \& Molecular Biosciences, University of Queensland, St. Lucia, Australia. ${ }^{4}$ Gatton Campus Equine Unit, University of Queensland, Gatton Campus, Gatton, Qld 4343, Australia. ${ }^{5}$ Vaxine Pty., Ltd., Flinders Medical Centre, Adelaide, South Australia. ${ }^{6}$ Flinders Medical Centre and Flinders University, Bedford Park, South Australia.

Received: 22 September 2014 Accepted: 4 December 2014

Published online: 17 December 2014

\section{References}

1. Mackenzie JS, Lindsay MD, Coelen RJ, Broom AK, Hall RA, Smith DW: Arboviruses causing human disease in the Australasian zoogeographic region. Arch Virol 1994, 136:447-467.

2. Mackenzie JS, Johansen CA, Ritchie SA, van den Hurk AF, Hall RA: Japanese encephalitis as an emerging virus: the emergence and spread of Japanese encephalitis virus in Australasia. Curr Top Microbiol Immunol 2002, 267:49-73.

3. Solomon T: Flavivirus encephalitis. N Engl J Med 2004, 351:370-378.

4. Gould DJ, Byrne RJ, Hayes DE: Experimental infection of horses with Japanese encephalitis virus by mosquito bits. Am J Trop Med Hyg 1964, 13:742-746

5. Lam KH, Ellis TM, Williams DT, Lunt RA, Daniels PW, Watkins KL, Riggs CM: Japanese encephalitis in a racing thoroughbred gelding in Hong Kong. Vet Rec 2005, 157:168-173.

6. Miyake M: The pathology of Japanese encephalitis. A review. Bull World Hith Organ 1964, 30:153-160.

7. Yamanaka T, Tsujimura K, Kondo T, Yasuda W, Okada A, Noda K, Okumura T, Matsumura T: Isolation and genetic analysis of Japanese encephalitis virus from a diseased horse in Japan. J Vet Med Sci 2006, 68:293-295.

8. Konishi E, Shoda M, Kondo T: Analysis of yearly changes in levels of antibodies to Japanese encephalitis virus nonstructural 1 protein in racehorses in central Japan shows high levels of natural virus activity still exist. Vaccine 2006, 24:516-524.

9. Monath TP: Japanese encephalitis vaccines: current vaccines and future prospects. Curr Top Microbiol Immunol 2002, 267:105-138.

10. Tsai TF: New initiatives for the control of Japanese encephalitis by vaccination: minutes of a WHO/CVI meeting, Bangkok, Thailand, 13-15 October 1998. Vaccine 2000, 18(Suppl 2):1-25.

11. Fischer M, Casey C, Chen RT: Promise of new Japanese encephalitis vaccines. Lancet 2007, 370:1806-1808.

12. RIRDC 2006: Rural Industries Research \& Development Corporations Horse R\&D Plan 2006-2011. [https://rirdc.infoservices.com.au/items/06-114]

13. Lobigs M, Pavy M, Hall RA, Lobigs P, Cooper P, Komiya T, Toriniwa H, Petrovsky N: An inactivated Vero cell-grown Japanese encephalitis vaccine formulated with Advax, a novel inulin-based adjuvant, induces protective neutralizing antibody against homologous and heterologous flaviviruses. J Gen Virol 2010, 91:1407-1417.

14. Frost MJ, Zhang J, Edmonds JH, Prow NA, Gu X, Davis R, Hornitzky C, Arzey KE, Finlayson D, Hick P, Read A, Hobson-Peters J, May FJ, Doggett SL, Haniotis J, Russell RC, Hall RA, Khromykh AA, Kirkland PD: Characterization of virulent West Nile virus Kunjin strain, Australia, 2011. Emerg Infect Dis 2012, 18:792-800.

15. Roche SE, Wicks R, Garner MG, East IJ, Paskin R, Moloney BJ, Carr M, Kirkland P: Descriptive overview of the 2011 epidemic of arboviral disease in horses in Australia. Aust Vet J 2012, 91:5-13.

16. Toriniwa $\mathrm{H}$, Komiya T: Long-term stability of Vero cell-derived inactivated Japanese encephalitis vaccine prepared using serum-free medium. Vaccine 2008, 26:3680-3689.

17. Cooper P, Petrovsky N: Delta inulin: a novel, immunologically-active, stable packing structure comprising $\beta-D-[2 \rightarrow 1]$ polyfructo-furanosyl $a-D$ glucose polymers. Glycobiology 2011, 21:595-606.

18. Prow NA, Tan CSE, Wang W, Hobson-Peters J, Kidd L, Barton A, Hall RA, Bielefeldt-Ohmann $\mathrm{H}$ : Natural exposure of horses to mosquito-borne flaviviruses in South-East Queensland, Australia. Int J Environ Res Public Health 2013, 10:4432-4443.

19. Hall RA, Broom AK, Hartnett AC, Howard MJ, Mackenzie JS: Immunodominant epitopes on the NS1 protein of MVE and KUN viruses serve as targets for a blocking ELISA to detect virus specific antibodies in sentinel animal serum. J Virol Methods 1995, 51:201-210.

20. Blitvitch BJ, Bowen RA, Marlenee NL, Hall RA, Bunning ML, Beaty BJ: Epitope-blocking enzyme-linked immunosorbent assays for detection of West Nile virus antibodies in domestic mammals. J Clin Microbiol 2003, 41:2676-2679.

21. APVMA. 2014. Australian Pesticides and Veterinary Medicines Authority Guiidelines for registration of new veterinary vaccines [http://apvma.gov. au/node/1041]

22. Barton AJ, Prow NA, Hall RA, Kidd L, Bielefeldt-Ohmann H: A case of Murray Valley encephalitis in a two-year old Australian stock horse in South-East Queensland. Aus Vet $J$, in press.

23. Prow NA, Hewlett EK, Faddy HM, Coiacetto F, Wang W, Cox T, Hall RA, Bielefeldt-Ohmann $\mathrm{H}$ : The Australian public is still vulnerable to emerging virulent strains of West Nile virus. Front Public Health 2014, 2:146.

24. Petrovsky N, Larena M, Siddharthan V, Prow NA, Hall RA, Lobigs M, Morrey J: An inactivated cell culture Japanese encephalitis vaccine (JE-ADVAX) formulated with delta inulin adjuvant provides robust heterologous protection against West Nile encephalitis via cross-protective memory B cells and neutralizing antibody. J Virol 2013, 87:10324-10333.

25. Lobigs M, Larena M, Alsharifi M, Lee E, Pavy M: Live chimeric and inactivated Japanese encephalitis virus vaccines differ in their crossprotective values against Murray Valley encephalitis virus. J Virol 2009, 83:2436-2445

26. Karaqianni AE, Kapetanovic R, McGorum BC, Hume DA, Pirie SR: The equine alveolar macrophage: functional and phenotypic comparisons with peritoneal macrophages. Vet Immunol Immunopathol 2013, 155:219-228.

27. Gard GP, Marshall ID, Walker KH, Acland HM, Saren WG: Association of Australian arboviruses with nervous disease in horses. Aust Vet J 1977, 53:61-66.

28. Gordon AN, Marbach CR, Oakey J, Edmunds G, Condon K, Diviney SM, Williams DT, Bingham J: Confirmed case of encephalitis caused by Murray Valley encephalitis virus infection in a horse. J Vet Diagn Invest 2012, 24:431-436.

29. Holmes JM, Gilkerson JR, El Hage CM, Slocombe RF, Muurlink MA: Murray Valley encephalomyelitis in a horse. Aust Vet J 2012, 90:252-254. 
30. Selvey LA, Dailey L, Lindsay M, Armstrong P, Tobin S, Koehler AP, Markey PG, Smith DW: The changing epidemiology of Murray Valley encephalitis in Australia: the 2011 outbreak and a review of the literature. PLOS Neg/ Trop Dis 2014, 8:e2556.

31. Poidinger M, Hall RA, Mackenzie JS: Molecular characterization of the Japanese encephalitis serocomplex of the flavivirus genus. Virology 1996, 218:417-421.

32. Blasco E, Lambot M, Barrat J, Cliquet F, Brochier B, Renders C, Krafft N, Bailly J, Munier M, Pastoret P-P, Aubert MFA: Kinetics of humoral immune response after rabies VR-G oral vaccination of captive fox cubs (Vulpes vulpes) with or without maternally derived antibodies against the vaccine. Vaccine 2001, 19:4805-4815.

33. Endsley JJ, Roth JA, Ridpath J, Neill J: Maternal antibody blocks humoral but not T cell responses to BVDV. Biologicals 2003, 31:123-125.

34. Filho OA, Megid J, Geronutti L, Ratti J Jr, Almeida MFA, Kataoka APAG, Martorelli LFA: Vaccine immune response and interference of colostral antibodies in calves vaccinated against rabies at 2, 4 and 6 months of age born from antirabies revaccinated females. Res Vet Sci 2012, 92:396-400.

35. Hodgins DC, Shewen PE: Vaccination of neonates: problem and issues. Vaccine 2012, 30:1541-1559.

36. Oura CAL, Wood JLN, Floyd T, Sanders AJ, Bin-Tarif A, Henstock M, Edwards L, Simmons $H$, Batten $C A$ : Colostral antibody protection and interference with immunity in lambs born from sheep vaccinated with an inactivated Bluetongue serotype 8 vaccine. Vaccine 2010, 28:2749-2753.

37. Siegrist CA: The challenges of vaccine responses in early life: selected examples. J Comp Pathol 2007, 137(Suppl 1):S4-S9.

38. Siegrist CA, Lambert PH: Maternal immunity and infant responses to immunization: factors influencing infant responses. Dev Biol Stand 1998, 95:133-139.

39. Wilkins PA, Glasser AL, McDonnell SM: Passive transfer of naturally acquired specific immunity against West Nile virus to foals in a semi-feral pony herd. J Vet Intern Med 2006, 20:1045-1047.

40. Brown AN, Kent KA, Bennett CJ, Bernard KA: Tissue tropism and neuroinvasion of West Nile virus do not differ for two mouse strains with different survival rates. Virology 2007, 368:422-430.

41. Weiner LP, Cole GA, Nathanson N: Experimental encephalitis following peripheral inoculation of West Nile virus in mice of different ages. J Hyg (Lond) 1970, 68:435-446.

42. Suen WW, Prow NA, Hall RA, Bielefeldt-Ohmann H: Mechanism of West Nile virus neuroinvasion: a critical appraisal. Viruses 2014, 6:2796-2825.

43. Shirafuji H, Kanehira K, Kamio T, Kubo T, Shibahara T, Konishi M, Murakami K, Nakamura Y, Yamanaka T, Kondo T, Matsumura T, Muranaka M, Katayama Y: Antibody responses induced by experimental West Nile virus infection with or without previous immunization with inactivated Japanese encephalitis vaccine in horses. J Vet Med Sci 2009, 71:969-974.

44. Larena M, Prow NA, Hall RA, Petrovsky N, Lobigs M: JE-ADVAX vaccine protection against Japanese encephalitis virus mediated by memory $B$ cells in the absence of CD8(+) T cells and pre-exposure neutralizing antibody. J Virol 2013, 87:4395-4402.

45. Angenvoort J, Brault AC, Bowen RA, Groschup MH: West Nile viral infection of equids. Vet Microbiol 2013, 167:168-180.

46. Bowen RA, Nemeth NM: Experimental infections with West Nile virus. Curr Opin Infect Dis 2007, 20:293-297.

47. Ellis PM, Daniels PW, Banks DJ: Japanese encephalitis. Vet Clin North Am Equine Pract 2000, 16:565-578.

48. Long MT, Gibbs EPJ, Mellemcamp MW, Bowen RA, Seino KK, Zhang S, Beachboard SE, Humphrey PP: Efficacy, duration, and onset of immunogenicity of a West Nile virus vaccine, live Flavivirus chimera, in horses with a clinical disease challenge model. Equine Vet J 2007, 39:491-497.

49. Kay BH, Pollitt CC, Fanning ID, Hall RA: The experimental infection of horses with Murray Valley encephalitis and Ross River viruses. Aust Vet J 1987, 64:52-55.

50. Seino KK, Long MT, Gibbs EP, Bowen RA, Beachboard SE, Humphrey PP, Dixon MA, Bourgeois MA: Comparative efficacies of three commercially available vaccines against West Nile Virus (WNV) in a short-duration challenge trial involving an equine WNV encephalitis model. Clin Vaccine Immunol 2007, 14:1465-1471.

51. Brandler S, Tangy F: Vaccines in development against West Nile virus. Viruses 2013, 5:2384-2409.

52. Hall RA, Nisbet DJ, Pham KB, Pyke AT, Smith GA, Khromykh AA: DNA vaccine coding for the full-length infectious Kunjin virus RNA protects mice against the New York strain of West Nile virus. Proc Natl Acad Sci U S A 2003, 100:10460-10464

53. Roby JA, Bielefeldt-Ohmann H, Prow NA, Chang DC, Hall RA, Khromykh AA: Increased expression of capsid protein in trans enhances production of single-round infectious particles by a West Nile virus DNA vaccine. J Gen Virol 2014, 95:2176-2191.

54. Siger L, Bowen RA, Karaca K, Murray MJ, Gordy PW, Loosmore SM, Audonnet JC, Nordgren RM, Minke JM: Assessment of the efficacy of a single dose of a recombinant vaccine against West Nile virus in response to natural challenge with West Nile virus-infected mosquitoes in horses. Am J Vet Res 2004, 65:1459-1462.

doi:10.1186/s13567-014-0130-7

Cite this article as: Bielefeldt-Ohmann et al: Safety and immunogenicity of a delta inulin-adjuvanted inactivated Japanese encephalitis virus vaccine in pregnant mares and foals. Veterinary Research 2014 45:130.

\section{Submit your next manuscript to BioMed Central and take full advantage of:}

- Convenient online submission

- Thorough peer review

- No space constraints or color figure charges

- Immediate publication on acceptance

- Inclusion in PubMed, CAS, Scopus and Google Scholar

- Research which is freely available for redistribution

Submit your manuscript at www.biomedcentral.com/submit
C) Biomed Central 